\title{
The occurrence of $\mathrm{P}, \mathrm{Al}$ and $\mathrm{Si}$ impurities in Australian iron ores: the goethite connection
}

\author{
MARK I. POWNCEBY ${ }^{1}$, JAMES R. MANUEL ${ }^{2}$, COLIN M. \\ MACRAE $^{3}$ AND NICK WILSON ${ }^{4}$ \\ ${ }^{1}$ CSIRO Mineral Resources, Private Bag 10, Clayton South \\ 3169, VIC, Australia. Mark.Pownceby@csiro.au \\ ${ }^{2}$ CSIRO Mineral Resources, 1 Technology Court, Pullenvale \\ 4069, QLD, Australia. James.Manuel@csiro.au \\ ${ }^{3}$ CSIRO Mineral Resources, Private Bag 10, Clayton South \\ 3169, VIC, Australia. Colin.Macrae@csiro.au \\ ${ }^{4}$ CSIRO Resources, Private Bag 10, Clayton South 3169, \\ VIC, Australia. Nick.Wilson@csiro.au
}

\begin{abstract}
Mining and recovery of Fe-oxides underpins Australia's mining sector. Declining production of high-grade hematite ores has led to an increasing reliance on lower grade, impurity-containing goethitic ores. In this study we determine the distribution and association of the critical impurities Al, $\mathrm{Si}$ and $\mathrm{P}$ within different goethite textural types in Australian iron ores. A detailed characterisation study using XRF and QXRD techniques to provide chemistry and mineralogy followed by hyperspectral EPMA to identify impurity element distributions and textural associations. In element maps a strong association between $\mathrm{P}, \mathrm{Al}$ and $\mathrm{Si}$ was noted and after follow-up quantitative analyses a coupled substitution mechanism for $\mathrm{P}, \mathrm{Al}$ and $\mathrm{Si}$ incorporation within goethite was proposed: $2 \mathrm{Si}^{4+}=\mathrm{P}^{5+}+\mathrm{Al}^{3+}$. Quantum mechanical modelling examining coupled $\mathrm{Al}$ and $\mathrm{P}$ incorporation indicated the most stable configuration was reached when $\mathrm{Al}^{3+}$ substituted for $\mathrm{Fe}^{3+}$ next to a P-induced vacancy defect. This preliminary result appears to support the coupled substitution model.
\end{abstract}

While the FEG-EPMA analyses offer preliminary conclusions regarding the possible mechanism(s) of $\mathrm{P}$ incorporation in goethite, the results could equally be explained by the presence of nanometre size inclusions of $\mathrm{P}-$, Al- and Si-rich phases or adsorbed species such as $\left[\mathrm{AlPO}_{3}\right]^{3+}$. If present, these would be below the $\sim 150 \mathrm{~nm}$ analytical resolution of the FEG-EPMA technique and when probed, would appear to be present as solid solution components. To determine conclusively the mechanism of $\mathrm{P}, \mathrm{Al}$ and $\mathrm{Si}$ incorporation requires examination of goethite-rich regions that are known to contain these impurities, via an imaging technique such as high-resolution SEM or a structural identification method such as TEM.

The exact type of substitution mechanism will have important implications in designing strategies for removing impurities from goethitic ores containing high levels of impurities. 